Old Dominion University

ODU Digital Commons

Dental Hygiene Faculty Publications

Dental Hygiene

2008

\title{
New Words to Promote Communication and Collaboration Among the Oral Health Care Team
}

Trisha Nunn

Michele L. Darby

Old Dominion University

Susan H. Kass

Connie L. Kracher

Linda S. Stewart

See next page for additional authors

Follow this and additional works at: https://digitalcommons.odu.edu/dentalhygiene_fac_pubs

Part of the Dental Public Health and Education Commons

\section{Repository Citation}

Nunn, Trisha; Darby, Michele L.; Kass, Susan H.; Kracher, Connie L.; Stewart, Linda S.; Symington, Don R.; and Westphal, Cheryl, "New Words to Promote Communication and Collaboration Among the Oral Health Care Team" (2008). Dental Hygiene Faculty Publications. 1.

https://digitalcommons.odu.edu/dentalhygiene_fac_pubs/1

\section{Original Publication Citation}

Nunn, T., Darby, M. L., Kass, S. H., Kracher, C. L., Nunn, T. J., Stewart, L. S., ... Westphal, C. (2008). New words to promote communication and collaboration among the oral health care team. Journal of Dental Education, 72(6), 641-642. 
Authors

Trisha Nunn, Michele L. Darby, Susan H. Kass, Connie L. Kracher, Linda S. Stewart, Don R. Symington, and Cheryl Westphal 


\section{New Words to Promote Communication and Collaboration Among the Oral Health Care Team}

Dear Dr. Alvares:

Clichés abound about the power of words. Spoken words, the result of air passing over contracted laryngeal muscles producing sound waves, are far from harmless. How we interpret the words we hear or choose the words we speak or write is the result of our experiences, beliefs, biases, values, culture, gender, and emotions. Each word we use is an opportunity for promoting understanding or misunderstanding. Instantaneously, the words we choose influence how others will act or react.

Members of the oral health care team have a history of antagonistic encounters with each other. Much of that history has been created by an emotionally charged vocabulary that often prohibits productive discussions of important health care issues. Even though the players, the conditions, and the challenges continue to change, our charged words are a barrier preventing us from collaborating to solve today's health care challenges.

The allied dental program directors who attended the American Dental Education Association (ADEA) Summit on Allied Dental Education, June 10-13, 2006, agreed that language affects the vision for allied dental education, and the need to use a common language more in line with moving the debate forward became apparent. Since language is used to frame any debate, current trends and thinking must be communicated to stimulate meaningful dialog on the proposed vision for allied dental education. ADEA, allied dental education faculty and program directors, and key partners have the opportunity to influence the language that we use. Just as ADEA has assumed leadership in promoting diversity and access to oral health care and helped to shape issues with skillful use of language, so too should ADEA become a leader in changing the language framing the future of allied dental education.
We are sometimes our own worst enemies when we use words to describe ourselves, our services, or our profession in less than empowering terms. Consider the image imparted by asking our patients or clients to come in for just a "prophy" or a simple cleaning or "scaling" rather than "initial care" or "preventive oral health care" or "nonsurgical periodontal care." The terms "prophy" and "cleaning" do not present the full range of dental hygiene preventive skills or the level of care that the service will provide for the patient. Likewise, we tend to speak of "deep cleaning" rather than "nonsurgical periodontal care"; of "checking the patient" as opposed to "evaluating outcomes of care"; of "plate, cap, or bridge" instead of "denture, crown, or prosthetic appliance"; etc.

Even among our own colleagues, we many times fail to distinguish the differences in education, certification, and licensure within the office structure. Primary members of the dental team are the dentist, dental assistant, dental hygienist, and dental laboratory technician. In the past, some have referred to the dental team as the dentist and the dental "auxiliaries" or even the dentist and the "girls," since the majority of allied dental personnel tend to be female. The Merriam-Webster Dictionary defines "auxiliary" as one who offers or provides help or functions in a subsidiary capacity. In today's modern dental practice, that is hardly the case. It seems the use of the term "auxiliary" has waned from most of our language, but it is still used occasionally among dentists and even among dental hygienists. And the use of "girls" to represent the dental hygienists and assistants in a dental practice is just plain sexist. We have come much further in gender and racial equality than this reference would suggest. The use of the word "girl" has no place in discussions of cotherapy, collaborative practice, sharing professional responsibility, evidence-based decision making, or 
the new potential for allied dental health professionals. Furthermore, with the career opportunities that allied dental professionals have available to explore today, the term no longer fits. It is time we and others started referring to allied dental personnel by their professional designations.

You want other examples? We tend to refer to our "job" instead of our "career" or "profession." We speak to students and fellow faculty members about "training" rather than "accredited education." We talk about "expanded duties or functions" rather than "expanded scope of practice." Before we reach out to others in dentistry and health care, we need to clean up our own language act, so to speak. How do we want the rest of the world to view the professions of dental assisting, dental hygiene, and dental laboratory technology? Do we want to be based in an "occupational model" or a "professional model"?

So how do we change the language of the debate to create opportunities for more productive discussions among the communities of interest? Developing a whole new professional language would be quite a task and is certainly not necessary. However, increasing awareness and understanding

Table 1. Old school words and phrases that should be retired and some appropriate substitutions

Old School

New School

prophy, cleaning, scaling

deep cleaning

checking the patient

plate, cap, bridge

dental auxiliaries

dentist and the girls

dental family

girl

job

training

expanded duties, functions

functions, duties

permitted, allowed

recall

fillings

novocaine

routine care

home care

x-ray

supervised practice

dental health

levels of supervision

polish initial care, preventive oral health care

nonsurgical periodontal care

evaluating outcomes of care

denture, crown, prosthetic appliance

allied dental personnel (dental assistant,

dental hygienist, dental laboratory technician)

oral health care team

oral health care team

professional title (care coordinator, dental

assistant, dental hygienist, dental laboratory

technician, etc.)

career, profession

accredited education

expanded scope of practice

service, therapies, procedures, responsibilities

within scope of practice

recare, continued care, periodontal

maintenance care

restorations

anesthesia

individualized care

self-care

radiograph

collaborative practice

oral health

levels of collaboration

selective extrinsic stain removal of how one professional perceives another might be a sensible approach. So here we take the first step: identifying phrases and words that trigger negativity, serve as barriers to clear communication, and hinder honest collaboration, and then offering potential alternative terms and phrases.

In Table 1, we have identified on the left side some emotionally charged, old school words and phrases that should be retired from our professional language; on the right side of the table, appropriate substitutions are offered. What other emotionally charged words can you add to this list? Challenge your colleagues, fellow practitioners and educators, and students alike to reflect on the language that you and others use. It could be an enlightening experience.

The table provides examples of words that don't necessarily reflect the best image of an oral health professional. Email other thoughts about professional language to newlanguage@adea.org.

Trisha Nunn, R.D.H., M.S.

Dean/Director

Utah College of Dental Hygiene

1176 S1480

Orem, UT 84057

801-426-8234 phone 801-224-5437 fax

tnunn@ucdh.edu

ADEA Council of Allied Dental Program Directors' Task Force on Collaboration, Innovation, and Differentiation

Michele L. Darby, R.D.H., M.S. Old Dominion University

Susan H. Kass, R.D.H., Ed.D. Miami Dade College

Connie L. Kracher, M.S.D., Ph.D. Indiana University-Purdue University, Fort Wayne

Trisha J. Nunn, R.D.H., M.S. Utah College of Dental Hygiene

Linda S. Stewart, M.S. University of North Carolina at Chapel Hill

Don R. Symington, C.D.T. Indian River Community College

Cheryl Westphal, R.D.H., M.S. New York University 